\title{
Research on Contemporary Public Art from the Perspective of Interaction
}

\author{
Zheng Wang \\ School of Architecture and Civil Engineering, Xiamen University, Xiamen, \\ 361005, China
}

\begin{abstract}
With the continuous improvement of the publicartistic needs, the construction of public art has been greatly developed in recent years. The public art gradually presents the characteristics of interactivity. This paper studies the interactive models of contemporary public art, including the models of contact-type interaction, experience-type interaction and devise-type interaction. The concept, characteristics and cases of each model are explored in the paper in order to provide some references for the related researchers.
\end{abstract}

Keywords:public art, interaction design, design strategy

\section{Introduction}

Public art is the art of behaviour which takes the human as the core value, the city as the public space, the public environment and public facilities as the object. Public art is the product of modern urban culture and urban life. It is also a concentrated expression of civic culture. Public art works not only show the formal beauty of the works of art, but also the intrinsic cultural value. In a certain sense, these works show the spirit of a city, district, street, the carrier of history and civilization, and the symbol of urban culture. Public art is a kind of public cultural symbols from the date of birth, is the characterization of social, political form, cultural value, the technological level of symbols, so it has a personal domain of art form in art works. Public works of art is not to allow artists to make their own personality, but a kind of art form of public appreciation and mass participation. It is necessary for the public to participate in the creation and construction of the place and the geographical features, and the interaction 
between the works and the audience. Publicity and interactivity are the most essential attributes of public art. Public art reflects contemporary people's cultural philosophy, aesthetic and humanistic care in a certain sense, development reflects the overall social pluralism and the level of science and technology. The significance of interactive public art highlights the experience of the "peopleoriented" communication.With the development of the times, the interaction of public art is further highlighted. In this paper, the interactive mode of public art is divided into mechanical interaction, interactive experience and creative interaction. We illustrate the concept, features and an example of each interaction model to show the richness of contemporary interactive public art.

\section{Contact-type interaction of contemporary public art: please touch}

Contact-type interaction model is the model of the public art author intentionally or unintentionally left some space for the audience at the beginning of the creationso that people can touch the distance. With the fast pace of modern life, people want to work in contact with the environment to seek relaxed feeling, tension and release the pressure of the spirit of life. The public art is able to meet the spiritual needs of the people. The public art has the character of affinity and positive dialogue with the public, so as to weaken the relationship between the subject and the object. The works of art often express the emotion of the artist, and resonate with the public through it. The meeting of the people and the work of art is the opportunity to communicate with the world, with others, and to share the same experience with each other. We realize the emotional communication and interpersonal communication. Mechanical interaction refers to the behavior of people and public works of art. People can access or directly into the works, and have a certain impact on them, especially those with practical function or to participate in the main sculpture. They encourage people's behavior. People can touch them by hands or sit in them. The contact with the public art will bring about joy for the children and the adults who touch or climb the public art which cannot be provided by the traditional public art with the signs of "No touch" and "No climbing".In the process of mechanical interaction, the feeling of artistic works should be safe first. It is not only physical and psychological harm to people. People will be willing to close contact. If the work gives people the feeling of danger, people will produce a sense of panic or disgust. The interaction between people and the public art will be weakened.Figure 1 shows the contacttype interaction of rickshaw sculpture in Beijing. 


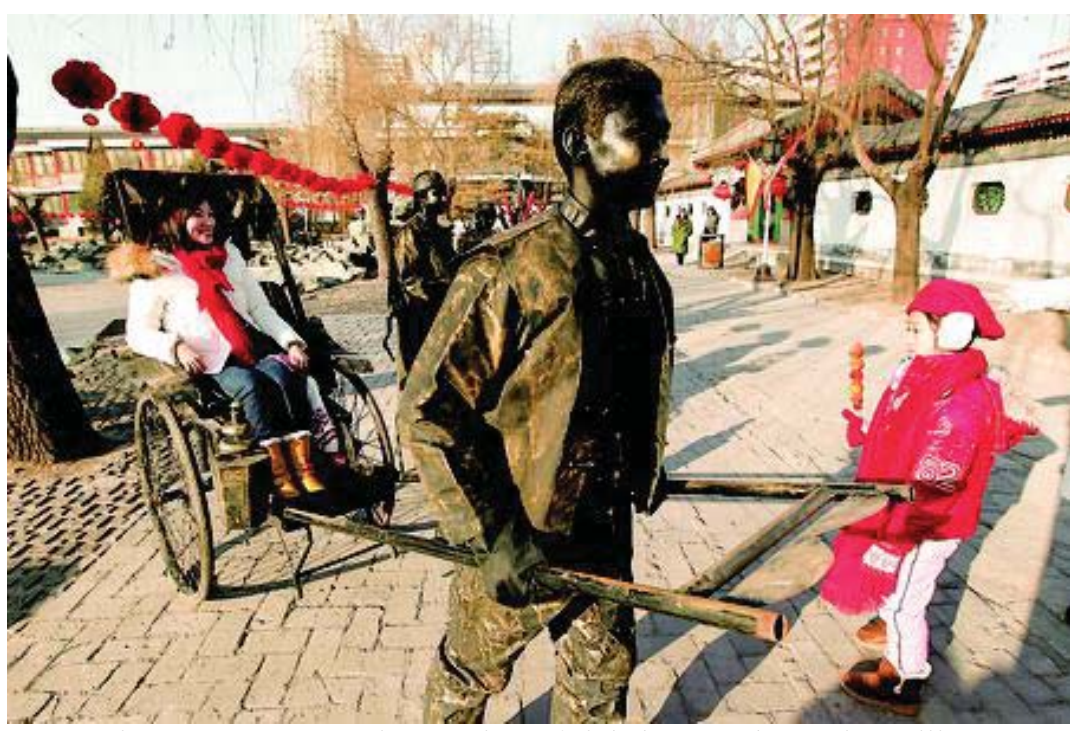

Fig. 1: Contact-typeinteraction of rickshaw sculpture in Beijing

\section{Experience-type interaction of contemporary public art: please feel}

Experience-type interaction is to allow the public to participate in the art, and even can operate it to obtain the unique feeling. With the help of new technology, we can interact with each other by means of virtual reality and digital interaction. Interactive public art has great media function, it is different from a traditional mode of public art, a traditional mode of public art is a simple process of information transmission, information from a single source to a single target audience, and the interaction of public art is a two-way circular type reciprocating mode, from the information source to the target audience to the source of information. Social networking sites, search engines and mobile phones to promote the progress of the public and beyond the time and space to interact with people and things, it has become an important source of information. Interactive public works of art is a dialogue between the audience and the machine, this process is two-way, reciprocating cycle. It is a system of information exchange. In the subway space, this kind of communication process presents a more centralized and efficient communication mode because of the particularity of space. The celadon bowl in Zhejiang Museum of the Shanghai World Expo combined the magic, science, art, technology into a device to present a unique feeling. It is shown in Figure 2. 

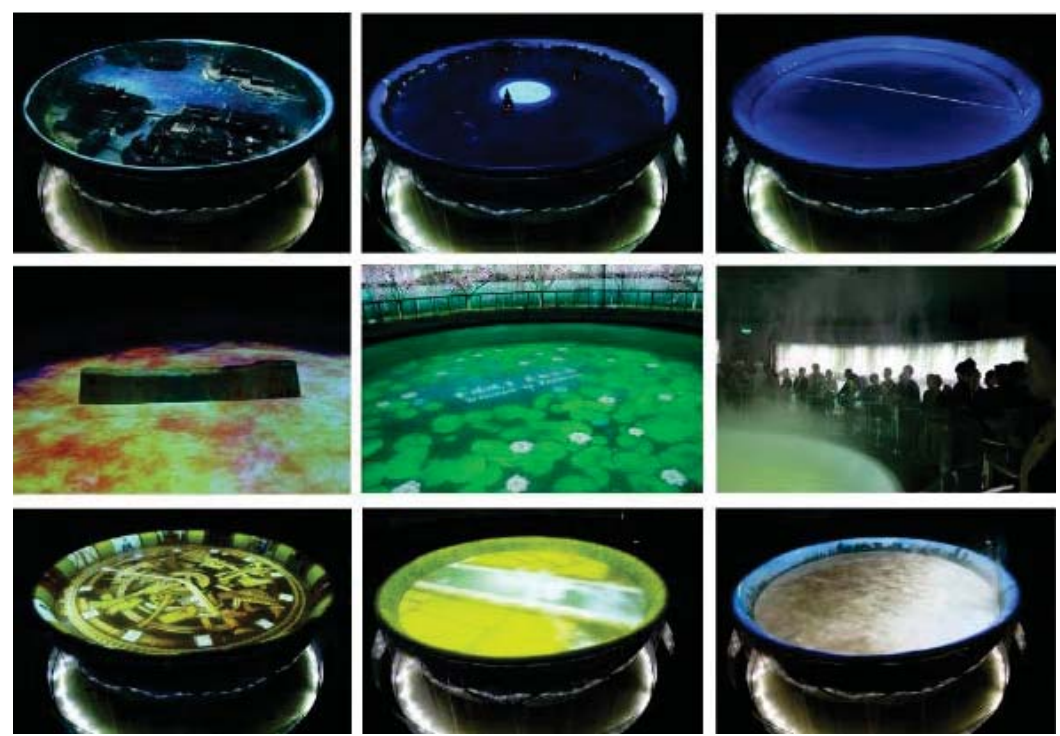

Fig. 2: Experience-typeinteraction of celadon bowl

\section{Devise-type interaction of contemporary public art: please design}

Devise-type interaction model refers to the public participation process of the public art, rather than just experience the use of the public art. In fact, every citizen can be the creator of public art. Because of the emergence of interactive art, the language has been realized. Duchamp, a pioneer of modern art, once said, "Art is done by the audience". In such a two-way communication environment, other than the creator of the work may also become part of the work. For example, AntFarm created a public art name Cadillac farm in 1997 which is shown in Figure 3. This work putten classic Cadillac cars into the soil. The artists allow visitors go into the car without any payment. In this way, arbitrary graffiti also became public works itself. The information from the artists issued to audience feedback is a complete and smooth process of interaction. This kind of public participation is considered as the representative of free spirit. The creation of public art interaction is bound to be the theme of the development of public art in the future, and this form of interaction is the most interactive form of the interaction, the highest public participation. Under the background of the new technology, the interaction between the public art and the transfer of the right to create and change the value of the technology, the interaction is not only a possibility, but also a necessary behavior. This kind of work is not linear narrative, but emphasizes the audience's subjective initiative. The core of interactive art is interactive. It emphasizes the public to participate in the arts to become a part of the creators who directly changes the public art. These similar features will make the interactive art become one of the most ideal public 
spaceart. It will bea good connection between public art and public space.It fully expresses the communication and interaction between the creator and the public to realize the interactive and democratic nature of public space art.

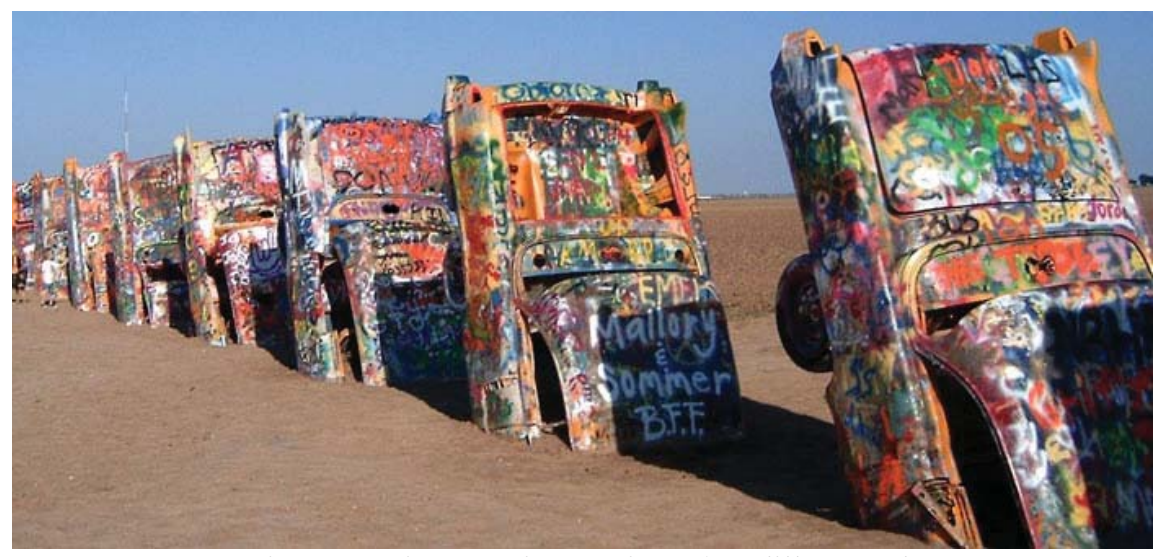

Fig. 3: Devise-type interaction of Cadillac ranch

\section{Conclusion}

Public art is the important carrier for people's behaviors. The modern city should be a kind of multicomponent syntheses with full interaction and creativity. The creation of public art should pay attention to the interaction with the public. The creator shouldappropriately increase of contact-type interaction, experience-type interaction and devise-type interaction of the contemporary public art so that the public can participate in the art and experience art beauty.

\section{References}

[1]Chen Gang, Interactive Connection Between Public Art and Audience, Sculpture, (4), pp. 54-55, 2016.

[2] Wen Yang, Huo Dan, Interactive Relationship Built in the Way of Public Art in Place-making, Architecture \& Culture, (11), pp. 212-213, 2016.

[3] Li Jun, A Re-Reading of Guernica - Views on Artistic Creation of Interactive Public Art, Art \& Design, (10), pp. 82-83, 2009.

[4] Pan Yingying, Meng Lei, Li Qingjun, Liao Chunmiao, Research on the design method of interactive public artin the context of information society, Journal of Wuxi Institute of Technology, 15(3), pp. 34-37, 2016.

[5] Shu Yue, Design Strategy of Interactive Public Art of Underground Space, Packaging Engineering, 37(12), pp. 93-96, 2016. 
[6]Chen Yuanyuan, Interactive Inhabited Environment Composition and Influence of New Media Art Interactive Forms in Public Space, Art \& Design, (12), pp. 143-144, 2013. 